\title{
AVALIAÇÃO DE INDICADORES DO CONTROLE DACONTAMINA- ÇÃO AMBIENTAL DA SALA DE OPERAÇÃO: UM ESTUDO PILOTO
}

\author{
AN EVALUATION OF CONTROL INDICATORS OF ENVIRONMENTAL \\ CONTAMINATION IN THE OPERATING ROOM: A PILOT STUDY
}

Luciane F. Nobre'; Cristina M. Galvão²; Kazuko U. Graziano³ \& Fabiana Corniani

\begin{abstract}
${ }^{1}$ Enfermeira. Aluna do Curso de Especialização em Enfermagem Clínico-Cirúrgica da Escola de Enfermagem de Ribeirão Preto da Universidade de São Paulo (EERP-USP). ${ }^{2}$ Docente da EERP-USP. ${ }^{3}$ Docente da Escola de Enfermagem da USP (São Paulo). ${ }^{4}$ Enfermeira. CorRespondênCIA: Cristina Maria Galvão. Escola de Enfermagem de Ribeirão Preto-USP. Avenida Bandeirantes, 3900 - CEP $14040-902$ Ribeirão Preto, São Paulo, Brasil. FAX: 55-16-6333271. e-mail crisgalv@glete.eerp.usp.br
\end{abstract}

NOBRE LF; GALVÃO CM; GRAZIANO KU \& CORNIANI F. Avaliação de indicadores do controle da contaminação ambiental da sala de operação: um estudo piloto. Medicina, Ribeirão Preto, 34: 183-193, abr./ jun.2001.

RESUMO: O controle da contaminação ambiental, na sala de operação, é uma das medidas de prevenção da infecção do sítio cirúrgico. Assim, o presente estudo teve como objetivo identificar se os padrões mínimos para o controle da contaminação ambiental estão sendo considerados pelos profissionais de saúde que atuam na unidade de Centro Cirúrgico. A investigação foi desenvolvida em um hospital geral, público; a coleta de dados realizou-se através de observação das cirurgias, utilizando instrumentos previamente elaborados, na especialidade de ginecologia e obstetrícia, no mês de janeiro de 2000, perfazendo um total de 23 procedimentos anestésicocirúrgicos observados. Realizamos uma análise descritiva e matemático-estatística, utilizando freqüência absoluta e porcentagem. Ao analisarmos o conjunto de itens do Padrão 1, que retrata a limpeza e montagem da sala de operação, e do Padrão 2, relativo aos princípios de assepsia cirúrgica, constatamos que a maioria dos procedimentos foi realizada pelos profissionais que atuavam na unidade, da forma preconizada pela literatura, entretanto, alguns itens avaliados evidenciaram a necessidade de reavaliação das práticas desenvolvidas pela equipe de saúde em relação ao controle da contaminação ambiental, bem como a atualização sobre os avanços técnico-científicos para o controle da infecção do sítio cirúrgico.

UNITERMOS: Monitoramento Ambiental. Infecção Hospitalar. Salas de Cirurgia.

\section{INTRODUÇÃ̃o}

O conhecimento e a abordagem do tema, infecção hospitalar, ao nosso ver, são cruciais para os profissionais da área de saúde principalmente devido a sua importância para o controle da qualidade da assistência prestada ao cliente/paciente.

$\mathrm{O}$ Centro Cirúrgico $(\mathrm{CC})$ devido à realização de vários procedimentos invasivos, é uma unidade que deve receber uma atenção especial, para não haver risco de o paciente adquirir uma infecção ${ }^{(1)}$.
A finalidade do controle ambiental da unidade de CC é isentar o paciente do risco de adquirir uma infecção hospitalar durante o procedimento anestésico- cirúrgico ${ }^{(2)}$, pois é, durante esse período, que a possibilidade de se ter uma contaminação ambiental é maior, devido ao número e trânsito de pessoas na Sala de Operação (SO), abertura de portas constantemente, o que promove a turbulência do ar e aumenta a quantidade e o movimento de microrganismos no ambiente, e por estar a ferida cirúrgica exposta ao contingente microbiano proveniente do ambiente e da equipe ci- 
rúrgica. Assim, fatores de risco de infecção hospitalar, no paciente cirúrgico, são múltiplos e interligados.

Os estudiosos reconhecem que a maior parte das infecções hospitalares, inclusive a da ferida cirúrgica, é de origem endógena (70 a 80\%). A segunda causa de transmissão de infecção da ferida cirúrgica é veiculada principalmente pelas vias aéreas superiores e pelas mãos das pessoas da equipe cirúrgica ${ }^{(2)}$.

Outra causa de transmissão de infecção são os artigos médico- hospitalares, os quais devem ser controlados pelo adequado processamento, manuseio e esterilização. $\mathrm{O}$ ar ambiente é considerado por vários autores como o fator de menor importância na transmissão de infecção, mas devemos ter em mente que todos os fatores de risco para infecção devem ser considerados importantes a fim de haver um controle global $^{(2)}$.

O controle da contaminação ambiental no CC tem sido considerado como medida racional pelo CDC (Centers for Disease Control and Prevention) dos Estados Unidos da América ${ }^{(3)}$.

Vários procedimentos podem ser executados para que tenhamos um controle da contaminação ambiental na SO como: a limpeza da sala, englobando a dos equipamentos, mobiliário, piso, paredes e portas; controlar o número, acesso e trânsito de pessoas na SO; a abertura de portas; controlar o sistema de ventilação, seguindo as normas vigentes, garantindo, assim, a filtração e troca constante do ar, bem como a paramentação adequada da equipe cirúrgica, dentre outros.

Para uma avaliação do controle da contaminação ambiental na SO e conseqüente controle da qualidade de assistência prestada ao cliente, pelos profissionais da área de saúde, é necessária a utilização de alguns padrões. Nos Estados Unidos da América, a elaboração de padrões que guiem a prática de enfermagem tem sido uma constante e, "desde a década de 70 a AORN (Association of Operating Room Nurses) e a ANA (American Nursing Association) publicam padrões referentes à prática e administração da enfermagem na sala de operação"(4).

Concordamos que "a avaliação da qualidade da assistência prestada ao paciente constitui-se em requisito essencial para a enfermagem como profissão, se esta desejar manter a responsabilidade pelas suas ações"(5). Assim, é necessário buscar a boa qualidade da assistência prestada ao cliente e oferecer à população serviço de menor risco e maior eficácia.

Frente ao exposto, o presente estudo teve como objetivo identificar se os padrões mínimos para o con- trole da contaminação ambiental, na sala de operação, estão sendo levados em consideração pelos profissionais que atuam naquela unidade de um centro cirúrgico.

\section{PROCEDIMENTO METODOLÓGICO}

A presente investigação foi realizada em uma instituição hospitalar pública, de uma cidade do interior paulista, após aprovação do projeto de pesquisa pelo seu Comitê de Ética em Pesquisa e autorização da Divisão de Enfermagem.

A coleta de dados foi realizada através de observação das cirurgias, na especialidade de ginecologia e obstetrícia, e de como se processou o controle da contaminação ambiental.

Foram utilizados para direcionar a coleta de dados os padrões: Padrão 1 - "A Sala de Operação está limpa e equipada adequadamente para realizarse o ato anestésico- cirúrgico" e Padrão 2 - "Na Sala de Operação, os princípios da assepsia cirúrgica são respeitados", elaborados por Galvão \& Sawada, $1995^{(4)}$. O primeiro padrão aborda a questão da limpeza da $\mathrm{SO}$ e a checagem dos equipamentos elétricos e fontes de gases. $\mathrm{O}$ segundo padrão refere-se aos princípios de assepsia cirúrgica relacionados à montagem da SO, preparo da equipe cirúrgica e campo operatório, manuseio de material e instrumental estéreis e controle do tráfego.

Para a coleta de dados elaboramos dois instrumentos, a saber:

- instrumento 1: inclui os indicadores do controle da contaminação ambiental da SO (anexo 1);

- instrumento 2: inclui os critérios destinados a indicar o valor a ser atribuído ao conjunto de itens de cada indicador do instrumento 1 (anexo 2).

A pesquisa foi desenvolvida na primeira semana de janeiro de 2000 (com exceção do sábado e do domingo), das 7:00 horas até aproximadamente às 18:00 horas. O tempo médio, desde a montagem da SO até o término da limpeza concorrente, foi de uma hora e meia para cada cirurgia, perfazendo um total de 23 procedimentos anestésico- cirúrgicos observados.

\section{RESULTADOS E DISCUSSÃO}

$\mathrm{Na}$ Tabela I, apresentamos o tipo de anestesia e cirurgia dos procedimentos observados. Constatamos uma diversidade de procedimentos cirúrgicos, sendo a raquianestesia e a geral as mais utilizadas. 


\begin{tabular}{|c|c|c|c|c|}
\hline \multirow[b]{2}{*}{ Tipo de cirurgia } & \multicolumn{3}{|c|}{ Tipo de anestesia } & \multirow[b]{2}{*}{ Total } \\
\hline & Raqui & $\begin{array}{l}\text { Raqui e } \\
\text { Geral }\end{array}$ & Geral & \\
\hline Histerectomia total, abdominal (HTA) + apendicectomia & 1 & & & 1 \\
\hline Burch + Colperineoplastia posterior (CPPP) & 2 & & & 2 \\
\hline $\begin{array}{l}\text { Histerectomia total, vaginal (HTV) + Colperineoplastia } \\
\text { anterior e posterior (CPPAP) }\end{array}$ & 1 & & & 1 \\
\hline Cesárea & 2 & & & 2 \\
\hline Mastoplastia bilateral, redutora & & & 1 & 1 \\
\hline CPPAP & 2 & & & 2 \\
\hline $\begin{array}{l}\text { Laparoscopia diagnóstica (LPS-D) + exérese de corpo } \\
\text { lúteo }\end{array}$ & & & 1 & 1 \\
\hline LPS-D + exérese de cisto benigno & & & 1 & 1 \\
\hline HTA & 1 & 2 & & 3 \\
\hline LPS-D + Histeroscopia (HSC) & & & 1 & 1 \\
\hline Laqueadura tubárea via laparoscópica (LTL) & & & 3 & 3 \\
\hline LPS-D + lise de aderência + biópsia do ovário esquerdo & & & 1 & 1 \\
\hline HSC para exérese de pólipo endometrial & 1 & & & 1 \\
\hline LPS-D & & & 1 & 1 \\
\hline LPS-D + miólise & & & 1 & 1 \\
\hline HTV + CPPP & 1 & & & 1 \\
\hline TOTAL & 11 & 2 & 10 & 23 \\
\hline
\end{tabular}

A Tabela II apresenta os valores obtidos na análise do Padrão 1.

Em relação à limpeza preparatória, não foi possível observá-la, já que ela é efetuada no plantão noturno, no hospital investigado (item 1).

Na limpeza operatória (item 2), a maioria dos procedimentos preconizados foi realizada, quando houve necessidade. Observamos que ela não foi efetuada em seis cirurgias, nas quais não foi realizada remoção mecânica da sujidade presente ao redor do campo operatório e nem aplicação de desinfetante sobre a matéria orgânica em questão.

A limpeza operatória é importante para se ter o controle da transmissão de microrganismos por contato direto e indireto e pelo ar ambiente. Ela deve incluir "a remoção mecânica da matéria orgânica que porventura espalhou-se além do campo operatório, seja diretamente nas superfícies, seja por compressas e outros artigos sujos, sendo a remoção mecânica o principal objetivo"(6).

Na presença de matéria orgânica, o Ministério da Saúde recomenda que as superfícies fixas (piso, parede, teto, porta, etc) sofram um processo de desinfecção (remoção mecânica de sujidade, seguida de limpeza com produto desinfetante) ou descontaminação localizada (aplicação do desinfetante sobre a matéria orgânica, deixando o tempo necessário para a ação microbicida, e posterior completa remoção) ${ }^{(7)}$.

A primeira forma de limpeza preconizada pelo Ministério da Saúde é a mais adequada para a sala de operação, durante o procedimento cirúrgico, pois devido às características do trabalho, não é possível, na maioria das vezes, aguardar o tempo de ação do desinfetante; quando ocorre sujidade em superfícies verticais, não existe uma forma de se aplicar o desinfetante sem que ele escorra. A principal ação preconizada, em tais situações, é a remoção mecânica ${ }^{(3)}$.

Os estudiosos, atualmente, enfatizam a importância da remoção mecânica da sujidade e alertam para as consequiências inerentes ao uso indiscriminado dos desinfetantes ${ }^{(6)}$.

A limpeza operatória é crucial, pois é sabido que a contaminação da ferida cirúrgica ocorre na sala de operação ou nas primeiras 24 horas após o procedi- 


\begin{tabular}{|c|c|c|c|c|c|c|c|c|c|c|}
\hline \multicolumn{11}{|c|}{$\begin{array}{l}\text { Tabela II: Distribuição dos valores obtidos na análise do Padrão } 1 \text { "A Sala de Operação está limpa e } \\
\text { equipada adequadamente para realizar-se o ato anestésico-cirúrgico" segundo os seus itens de } \\
\text { avaliação. }\end{array}$} \\
\hline \multirow{2}{*}{ Itens } & \multicolumn{2}{|c|}{ Sim } & \multicolumn{2}{|c|}{ Parcialmente } & \multicolumn{2}{|c|}{ Não } & \multicolumn{2}{|c|}{ Não se aplica } & \multicolumn{2}{|c|}{ Total } \\
\hline & $\mathrm{N}$ & $\%$ & $\mathrm{~N}$ & $\%$ & $\mathrm{~N}$ & $\%$ & $\mathrm{~N}$ & $\%$ & & $\%$ \\
\hline 1 - Limpeza preparatória & & & & & & & 23 & 100 & 23 & 100 \\
\hline 2 - Limpeza operatória & 17 & 74 & & & 6 & 26 & & & 23 & 100 \\
\hline 3 - Limpeza concorrente & 4 & 17 & 19 & 83 & & & & & 23 & 100 \\
\hline 4 - Limpeza terminal & & & & & & & 23 & 100 & 23 & 100 \\
\hline $\begin{array}{l}5 \text { - Testagem de equipa- } \\
\text { mentos }\end{array}$ & 23 & 100 & & & & & & & 23 & 100 \\
\hline Total & 44 & 38,2 & 19 & 16,5 & 6 & 5,2 & 46 & 40 & 115 & 100 \\
\hline
\end{tabular}

mento cirúrgico, razão pelo qual a remoção mecânica de matéria orgânica das superfícies é fundamental, e impedirá o ressecamento da mesma no ambiente e a conseqüente formação de partículas contaminantes ${ }^{(6)}$.

Em relação à limpeza concorrente (item 3), apenas em quatro cirurgias, todos os procedimentos foram realizados adequadamente. Os procedimentos inadequados observados foram:

- lixo e hamper não revisados e o último, também, não identificado;

- o piso foi limpo somente nos locais em que as pessoas transitavam;

- artigos médico-hospitalares, de diferentes natureza foram colocados no mesmo "galeteiro" pelo membro da equipe médica;

- separação dos artigos médico-hospitalares feita pelo membro da equipe médica;

- limpeza dos mobiliários, utilizando-se um propé, realizada por um membro da equipe médica.

A limpeza concorrente é aquela "realizada ao término de cada cirurgia. Envolve as tarefas de retirada do material sujo da sala, limpeza das superfícies horizontais dos móveis e equipamentos, limpeza do piso e remontagem da SO para o próximo evento"(3).

Convém ressaltar, ainda, que todo procedimento cirúrgico deve ser considerado como contaminado, exigindo-se, assim, as necessárias medidas-padrão de precauções $^{(8)}$.

No presente estudo, observamos a torção manual dos panos utilizados para a limpeza do piso e a utilização de luvas de procedimento como Equipamento de Proteção Individual (EPI) nesta atividade; esses mesmos aspectos foram encontrados no estudo de Barbosa, $1999^{(6)}$. A autora ressalta a exposição dos trabalhadores aos riscos biológicos ocupacionais, bem como o uso inadequado de EPI como barreira de proteção.

Em relação à limpeza terminal (item 4), não foi possível observar, já que ela é realizada no final de semana (período excluído na ocasião da coleta de dados).

A testagem dos equipamentos elétricos, fontes de gases, ar comprimido e vácuo (item 5), em todas as cirurgias, foi realizada adequadamente pelo circulante da SO.

Em um estudo ${ }^{(9)}$ sobre monitorização da SO, algumas vantagens foram apontadas, quando há verificação do funcionamento de equipamentos, anterior ao procedimento anestésico-cirúrgico: êxito e eficiência no trabalho; redução de tempo cirúrgico; rapidez no atendimento; redução do estresse da equipe cirúrgica e segurança do paciente nas intervenções cirúrgicas.

Ao término da apresentação dos resultados do Padrão 1, considerando o conjunto de itens avaliados (Tabela II), podemos afirmar que a maioria $(38,2 \%)$ dos procedimentos foi realizada, quando houve necessidade.

A Tabela III apresenta os valores obtidos na análise do Padrão 2.

Em relação à manutenção das técnicas assépticas, na montagem da SO (item 1), na maioria das cirurgias, ela aconteceu, embora, em uma cirurgia, um membro da equipe cirúrgica ajudou a montar a mesa cirúrgica; estando sem máscara durante o procedimento, tendo, ainda, ficado conversando em cima do material.

A integridade da esterilidade dos artigos depende do empacotamento adequado e de uma exposição 
mínima, sendo que o invólucro deve ser removido na sala de cirurgia, imediatamente antes de sua utilização ${ }^{(10)}$.

Quanto ao uso do uniforme privativo pela equipe cirúrgica e de enfermagem (item 2), na maioria das cirurgias ele foi utilizado de forma incorreta, a saber:

- o gorro não foi usado adequadamente, ficando parte do cabelo para fora;

- não-utilização de propé durante o procedimento anestésico- cirúrgico;

- a máscara permaneceu somente na boca, não cobrindo o nariz;

- ausência do uso da máscara durante o procedimento anestésico-cirúrgico.

O uso da máscara cirúrgica justifica-se por dois aspectos: protege o paciente da contaminação (principalmente quando a incisão cirúrgica está aberta) por microrganismos oriundos do nariz e da boca dos profissionais, liberados no ambiente, quando eles falam, tossem e respiram; protege as mucosas dos profissionais de respingamentos de secreções provenientes do paciente durante o procedimento cirúrgico ${ }^{(3)}$.

Em relação ao uso de gorros, recomenda-se sua utilização com o intuito de evitar a contaminação do sítio cirúrgico por cabelo ou microbiota presente nele, apesar de não existirem estudos que comprovem sua eficiência ${ }^{(11)}$. O gorro deve ser bem adaptado, permitindo que os cabelos sejam totalmente cobertos ${ }^{(10)}$.

O uso de propés é atualmente uma questão polêmica, uma vez que ainda se fazem necessários estudos criteriosos para que esta prática seja abolida. A forma como os propés vêm sendo utilizados não concorre para o controle de infecção hospitalar, pois os profissionais pisam em secreções orgânicas na sala de operação, e as disseminam para as outras áreas do $\mathrm{CC}$, áreas nas quais não só transitam pessoas que utilizam propés como também, pessoas que não os utilizam. O material com que eles são confeccionados não se constituiu barreira microbiológica eficiente ${ }^{(3)}$.

Em relação à escovação das mãos pela equipe cirúrgica (item 3), observamos que ela foi realizada de acordo com o preconizado em apenas quatro cirurgias. Em sete cirurgias, a escovação das mãos não foi realizada por alguns membros da equipe cirúrgica. Em doze cirurgias, ela não foi realizada adequadamente, já que era efetuada em poucos minutos, não envolvendo, muitas vezes, as unhas.

Na primeira cirurgia do dia, a escovação deve durar dois minutos com solução degermante, adequa- da, escova estéril e contemplar as áreas das mãos e antebraços $^{(10)}$.

A remoção mecânica de sujidade pode ser feita pela escovação ou fricção, sendo que a primeira somente é necessária nos leitos subungueais e espaços interdigitais; as mãos e antebraços devem ser apenas friccionados, evitando-se, assim, possíveis lesões devido ao emprego de escova. Esse processo deve durar, criteriosamente, cinco minutos, para o primeiro procedimento cirúrgico, e três minutos para os outros procedimentos, com agente contendo clorexidina, iodóforos ou solução alcoólica ${ }^{(11)}$.

O processo clássico, mencionado acima, está sendo substituído pela fricção do degermante sobre a pele, a qual pode ser realizada com as mãos dos profissionais ou com esponja vegetal, respeitando o tempo de ação da solução empregada conforme determinação do fabricante; tal substituição é possível devido à ação química do degermante sobre a microbiota da pele sem depender da ação mecânica, realizada pela escovação ${ }^{(12)}$.

No presente estudo, observamos que a paramentação cirúrgica (item 4 ) foi realizada adequadamente na maioria das cirurgias. Somente em quatro cirurgias, observamos falhas; em uma cirurgia, um membro da equipe cirúrgica não amarrou a opa adequadamente e, em três cirurgias, um membro da equipe cirúrgica contaminou o punho da opa, colocando a mão sem estar enluvada.

O uso da paramentação cirúrgica é uma forma coerente de prevenção de transmissão de contaminação e de infecção, tanto para o profissional como para o paciente, e o uso adequado está relacionado, também, com a garantia da manutenção da assepsia ${ }^{(3)}$.

Quanto aos procedimentos relacionados ao preparo do campo operatório (item 5), notamos que eles foram executados adequadamente na maioria das cirurgias. Observamos que, em duas cirurgias, após a anti-sepsia da pele do paciente, foram colocados, primeiro, os campos estéreis da parte distal e, após, aqueles ao redor do local cirúrgico. No transcorrer de outra cirurgia, um membro da equipe cirúrgica limpou o rosto no campo operatório da parte distal.

Em relação ao manuseio de materiais estéreis e instrumentos pela equipe cirúrgica, durante o ato cirúrgico (item 6), em uma cirurgia, foi passado um banco por cima da mesa operatória.

O tráfego de pessoal na sala de operação (item 7), na maioria das cirurgias, não foi controlado, o acesso e o trânsito de pessoas não foram restritos, além de 


\begin{tabular}{|c|c|c|c|c|c|c|c|c|c|c|}
\hline \multicolumn{11}{|c|}{$\begin{array}{l}\text { Tabela III: Distribuição dos valores obtidos na análise do Padrão } 2 \text { "Na Sala de Operação os princípios da } \\
\text { assepsia cirúrgica são respeitados" segundo os seus itens de avaliação. }\end{array}$} \\
\hline \multirow{2}{*}{ Itens } & \multicolumn{2}{|c|}{ Sim } & \multicolumn{2}{|c|}{$\begin{array}{l}\text { Parcial- } \\
\text { mente }\end{array}$} & \multicolumn{2}{|c|}{ Não } & \multicolumn{2}{|c|}{ Não se aplica } & \multicolumn{2}{|c|}{ Total } \\
\hline & $\mathrm{N}$ & $\%$ & $\mathrm{~N}$ & $\%$ & $\mathrm{~N}$ & $\%$ & $\mathrm{~N}$ & $\%$ & $\mathrm{~N}$ & $\%$ \\
\hline $\begin{array}{l}1 \text { - Técnicas assépticas na montagem } \\
\text { da sala de operação }\end{array}$ & 22 & 95,6 & 1 & 4,3 & & & & & 23 & 100 \\
\hline 2 - Uso do uniforme privativo & 2 & 8,7 & 21 & 91,3 & & & & & 23 & 100 \\
\hline 3 - Escovação das mãos & 4 & 17 & 12 & 52 & 7 & 31 & & & 23 & 100 \\
\hline 4 - Paramentação cirúrgica & 19 & 83 & 4 & 17 & & & & & 23 & 100 \\
\hline 5 - Preparo do campo operatório & 20 & 87 & 3 & 13 & & & & & 23 & 100 \\
\hline $\begin{array}{l}6 \text { - Manuseio de materiais e instru- } \\
\text { mentos estéreis }\end{array}$ & 22 & 95,6 & 1 & 4,4 & & & & & 23 & 100 \\
\hline $\begin{array}{l}7 \text { - Controle de tráfego na sala de } \\
\text { operação }\end{array}$ & 8 & 35 & 15 & 65 & & & & & 23 & 100 \\
\hline $\begin{array}{l}8 \text { - Controle de temperatura e umi- } \\
\text { dade do ar ambiente }\end{array}$ & & & & & & & 23 & 100 & 23 & 100 \\
\hline TOTAL & 97 & 52,7 & 57 & 30,9 & 7 & 3,8 & 23 & 12,5 & 184 & 100 \\
\hline
\end{tabular}

as conversas e movimentos das pessoas não terem diminuído durante o ato cirúrgico.

$\mathrm{Na} \mathrm{SO}$, deve-se manter o menor número de pessoas para redução do risco de contaminação ambiental, a movimentação do pessoal, reduzída, e as portas devem ser fechadas durante o ato anestésico-cirúrgico ${ }^{(10)}$.

Os dados evidenciados, na presente investigação, estão de acordo com um estudo, ${ }^{(13)}$ no qual se constatou índice expressivo de inadequação para o controle do tráfego de pessoal na $\mathrm{SO}$ e a manutenção das portas fechadas $(42,9 \%)$.

Quanto à temperatura e à umidade do ar ambiente (item 8), não houve parâmetros, na SO, para podermos analisá-las. O controle do ar na SO é recomendado há mais de 100 anos, pois é sabido que o maior risco de contaminação ocorre durante o ato cirúrgico devido à liberação de microrganismos oriundos do pessoal, na incisão cirúrgica aberta ${ }^{(3)}$.

Os parâmetros do controle do ar devem ser monitorados, diariamente, através de equipamentos capazes de medir a umidade, a temperatura e o volume correto de trocas do ar por hora, bem como devem ser observadas as queixas de desconforto do paciente e do pessoal atuante na $\mathrm{SO}^{(10)}$.

Além da regulamentação governamental do sistema de climatização do ar em SO e o controle dos parâmetros de funcionamento (temperatura, umida- de, etc) é fundamental a presença de profissionais capacitados para a manutenção e controle do sistema, nos hospitais ${ }^{(13)}$.

Em relação aos resultados do Padrão 2, ao analisarmos o conjunto de itens avaliados (Tabela III), constatamos que a maioria $(52,7 \%)$ dos procedimentos preconizados foi executada, quando houve necessidade, pelos profissionais que atuavam na Sala de Operação.

\section{CONSIDERAÇÕES FINAIS}

O presente estudo permitiu levantar aspectos que devem ser repensados pelos profissionais que atuam em CC em relação ao controle da contaminação ambiental da SO.

Os resultados evidenciados demonstraram a necessidade de reavaliação das práticas utilizadas, bem como a atualização sobre os avanços técnicocientíficos para o controle da infecção do sítio cirúrgico. Acreditamos que este estudo poderá fornecer subsídios para outros, especialmente quanto ao uso de padrões de assistência para o controle da contaminação ambiental na SO, e para a detecção de pontos críticos a serem enfocados em programas de educação continuada de toda a equipe de saúde que participa do processo de trabalho, em uma unidade de Centro Cirúrgico. 
NOBRE LF; GALVÃO CM; GRAZIANO KU \& CORNIANI F. An evaluation of control indicators of environmental contamination in the operating room: a pilot study Medicina, Ribeirão Preto, 34: 183-193, april/june 2001.

ABSTRACT: The control of environmental contamination in the operating room is an important measure to control infection in surgical sites. Therefore, this study aimed at identifying if minimum control patterns of environmental contamination are being considered by health professionals who perform their activities in operating rooms. The research was developed in a public general hospital and data were collected in the month of January, 2000, through the observation of gynecological and obstetrical operations using previously elaborated instruments, totaling 23 anaesthetic-surgical procedures observed. Subsequently, the authors carried out a descriptive and mathematical-statistical analysis using the absolute frequency and percentage. When analyzing the set of items for Pattern 1, which refers to the cleaning and preparation of the operating room, and those for Pattern 2, which are related to the principles of surgical asepsis, we found that most of the procedures were carried out by the professionals performing in the unit according to the patterns preconized by literature. However, some of the evaluated items showed the need for a re-evaluation of the practices developed by the health team regarding the control of environmental contamination as well as for the professionals' up-dating on technical and scientific advancements for infection control in surgical sites.

UNITERMS: Environmental Monitoring. Cross Infection. Operating Rooms

\section{REFERÊNCIAS BIBLIOGRÁFICAS}

1 - NOBRE LF \& GALVÃO CM Limpeza da sala de operação: aspecto relevante no controle da contaminação ambiental. In: Anais, 50 Congresso Brasileiro de Enfermagem, Salvador, BA, p. 230, 20-25 setembro 1998.

2 - GRAZIANO KU. Controle da contaminação ambiental da unidade de Centro Cirúrgico. Enfoque 1:19-22, 1994.

3 - LACERDA RA. Centro cirúrgico. In: FERNANDES AT; FERNANDES MOV \& RIBEIRO FILHO N. Infecção hospitalar e suas interfaces na área da saúde. Atheneu, São Paulo, p.789-818, 2000.

4 - GALVÃO CM \& SAWADA NO. Proposta de padrões mínimos do controle da contaminação ambiental da sala de operação. In: Anais, I Congresso Brasileiro de Enfermagem em Centro Cirúrgico, São Paulo, SP, p. 11-14, 4-7 julho 1995.

5 - AVELAR MC; PENICHE ACG; PAULA TAC \& VALINO MR. Avaliação da qualidade do cuidado de enfermagem em recuperação anestésica. In: Anais, I Congresso Brasileiro de Enfermagem em Centro Cirúrgico, São Paulo, SP, p. 15-27, 13-16 julho 1993.

6 - BARBOSA MH. Análise do procedimento de limpeza de sala de operações nos hospitais do Município de São Paulo: identificando mitos e rituais. Dissertação de Mestrado, Escola de Enfermagem da USP, São Paulo. p.1-119, 1999.
7 - BRASIL. MINISTÉRIO DA SAÚDE. Processamento de artigos e superfícies em estabelecimentos de saúde. Brasília, 1994.

8 - ASSOCIATION OF OPERATING ROOM NURSES (AORN). Práticas recomendadas para precauções-padrão baseadas em transmissão de patógenos no perioperatório. SOBECC 4: 12-15, 1999.

9 - SOUZA FM \& ALBUQUERQUE MT. Relato de experiência: monitorização da S.O. SOBECC 3: 22-25, 1998.

10 - AYLIFFE GAJ; LOWBURY EJL; GEDDES AM \& WILLIAMS JD. Controle de infecção hospitalar: manual prático. $3^{\underline{a}}$ ed. Revinter, Rio de Janeiro, p.147-157, 1998.

11 - ASSOCIAÇÃO PAULISTA DE ESTUDOS E CONTROLE DE INFECÇÃO HOSPITALAR (APECIH). Prevenção da infecção de sítio cirúrgico. São Paulo, 1995.

12 - GRAZIANO KU; SILVAA \& BIANCHI ERF. Limpeza, desinfecção, esterilização de artigos e anti-sepsia. In: FERNANDES AT; FERNANDES MOV \& RIBEIRO FILHO N. Infecção hospitalar e suas interfaces na área da saúde, Atheneu, São Paulo, p.266-305, 2000.

13 - MARTON ES; SANTOS MCL \& LACERDA RA. Controle ambiental em S.O. SOBECC 4: 16-22, 1999.

Recebido para publicação em 12/12/2000

Aprovado para publicação em 15/03/2001 


\section{ANEXO 1}

Indicadores do Controle da Contaminação Ambiental da Sala de Operação (SO)

Sala $\left(\mathrm{n}^{\circ}\right)$ :

Cirurgia Proposta:

Anestesia:

Cirurgia Realizada:

Data:

\begin{tabular}{|c|c|c|c|c|c|}
\hline ITENS DO PADRÃO & SIM & PARCIALMENTE & NÃO & $\begin{array}{l}\text { NÃO SE } \\
\text { APLICA }\end{array}$ & OBSERVAÇÕES \\
\hline $\begin{array}{l}\text { PADRÃO 1- A Sala de Operação está } \\
\text { limpa e equipada adequadamente para } \\
\text { realizar-se o ato anestésico- cirúrgico }\end{array}$ & & & & & \\
\hline $\begin{array}{l}\text { 1- A limpeza preparatória é realizada } \\
\text { adequadamente }\end{array}$ & & & & & \\
\hline $\begin{array}{l}\text { 2- A limpeza operatória é executada } \\
\text { sempre quando necessária }\end{array}$ & & & & & \\
\hline $\begin{array}{l}\text { 3-A limpeza concorrente é realizada } \\
\text { corretamente }\end{array}$ & & & & & \\
\hline $\begin{array}{l}\text { 4- A limpeza terminal é executada de } \\
\text { forma apropriada }\end{array}$ & & & & & \\
\hline $\begin{array}{l}\text { 5- Os equipamentos elétricos, fontes de } \\
\text { gases, ar comprimido e vácuo são testados }\end{array}$ & & & & & \\
\hline $\begin{array}{l}\text { PADRÃO 2- Na Sala de Operação, os } \\
\text { princípios da assepsia cirúrgica são respei- } \\
\text { tados }\end{array}$ & & & & & \\
\hline $\begin{array}{l}\text { 1- As técnicas assépticas na montagem da } \\
\text { SO são realizadas adequadamente }\end{array}$ & & & & & \\
\hline $\begin{array}{l}\text { 2- Os procedimentos relacionados ao pre- } \\
\text { paro da equipe cirúrgica (uso de uniforme } \\
\text { privativo) são executados adequadamente }\end{array}$ & & & & & \\
\hline $\begin{array}{l}\text { 3- Os procedimentos relacionados ao pre- } \\
\text { paro da equipe cirúrgica (escovação das } \\
\text { mãos) são realizados de forma correta }\end{array}$ & & & & & \\
\hline $\begin{array}{l}\text { 4- Os procedimentos relacionados ao pre- } \\
\text { paro da equipe cirúrgica (paramentação } \\
\text { cirúrgica) são executados adequadamente }\end{array}$ & & & & & \\
\hline $\begin{array}{l}\text { 5- Os procedimentos relacionados ao pre- } \\
\text { paro do campo operatório são executados } \\
\text { adequadamente }\end{array}$ & & & & & \\
\hline $\begin{array}{l}\text { 6- O manuseio de materiais estéreis e } \\
\text { instrumentos pela equipe cirúrgica, duran- } \\
\text { te o ato cirúrgico, é realizado de forma } \\
\text { correta }\end{array}$ & & & & & \\
\hline 7- O tráfego da SO é controlado & & & & & \\
\hline $\begin{array}{l}\text { 8- A temperatura e a umidade do ar am- } \\
\text { biente da SO são controladas }\end{array}$ & & & & & \\
\hline
\end{tabular}




\section{ANEXO 2 \\ Critérios para preenchimento do instrumento "Indicadores do Controle da Contaminação Ambiental da Sala de Operação"}

\section{PADRÃO 1- A Sala de Operação está limpa e equipada adequadamente para realizar-se o ato anestésico- cirúrgico}

\section{1- A limpeza preparatória inclui:}

- execução anteriormente ao início do primeiro ato anestésico-cirúrgico do dia;

- remoção mecânica de partículas de poeira com o uso de solução preconizada pelo Ministério da Saúde (MS);

- realização, principalmente, em superfícies horizontais, incluindo foco fixo central, mobiliário e equipamentos.

Total de itens=3: $\mathrm{SIM}=3 ; \mathrm{PARCIALMENTE}=2 ; \mathrm{NÃO}=1-0$

2- A limpeza operatória inclui:

- realização durante 0 ato anestésico-cirúrgico;

- remoção mecânica da sujidade presente ao redor do campo operatório;

- na presença de matéria orgânica, em superfícies horizontais, realizar a remoção mecânica, seguida de limpeza com produto desinfetante, preconizado pelo MS;

- na presença de matéria orgânica, em superfícies horizontais, aplicar desinfetante sobre a matéria, por período necessário à ação microbicida e depois removê-la.

Total de itens $=4$ : $\mathrm{SIM}=4$; PARCIALMENTE=3-2; NÃO=1-0

\section{3- A limpeza concorrente inclui:}

- execução ao término de cada cirurgia;

- material sujo é separado em galeteiros de acordo com sua natureza (borracha, vidro e metal) e encaminhado para a Central de Material;

- hamper de roupa é revisado, fechado, identificado e encaminhado para a lavanderia;

- lixo é revisado, fechado e encaminhado para o setor de coleta;

- todo o mobiliário, equipamentos, acessórios que entram em contato com o campo operatório, ou estão contaminados com matéria orgânica são limpos através de remoção mecânica, associada a solução preconizada pelo MS;

- piso é limpo com desinfetante recomendado pelo MS.

Total de itens=6: $\mathrm{SIM}=6 ;$ PARCIALMENTE $=5-3 ; \mathrm{NÃO}=2-0$

4- A limpeza terminal diária inclui:

- execução após a última cirurgia do dia;

- envolve a limpeza de todo o mobiliário, acessórios, equipamentos fixos e móveis presentes na SO;

- envolve a limpeza do piso e a limpeza das portas na altura das maçanetas.

Total de itens=3: $S I M=3 ;$ PARCIALMENTE=2; NÃO=1-0

\section{5- A limpeza terminal periódica:}

- envolve a limpeza das superfícies verticais (janelas, se houver, portas, teto, grades de entrada e saída do ar condicionado)

6- A testagem dos equipamentos elétricos, fontes de gases, ar comprimido e vácuo é realizada:

- no período que antecede a montagem da SO da primeira cirurgia do dia;

- uma vez por semana pelo serviço de manutenção.

Total de itens=2: $\operatorname{SIM}=2 ;$ PARCIALMENTE $=1 ; \mathrm{NÃO}=0$ 


\section{PADRÃO 2- Na Sala de Operação os princípios da assepsia cirúrgica são respeitados.}

1- A manutenção das técnicas assépticas na montagem da SO inclui:

- os materiais estéreis são abertos por métodos que mantêm a integridade e esterilização dos mesmos;

- os campos cirúrgicos são abertos com técnicas que mantêm sua esterilização;

- todos os materiais estéreis, quando introduzidos no campo operatório, são colocados e transferidos por métodos que mantêm sua integridade e esterilização;

- soluções líquidas são colocadas, lentamente, no recipiente que deve estar na extremidade da mesa, de forma que não molhe o campo operatório;

- o circulante de SO inspeciona a integridade do material estéril e a validade da esterilização antes de colocá-lo no campo operatório.

Total de itens=5: $\mathrm{SIM}=5 ; \mathrm{PARCIALMENTE}=4-2 ; \mathrm{NÃO}=1-0$

2- Os procedimentos relacionados ao preparo da equipe cirúrgica (uso de uniforme privativo), incluem:

- a equipe cirúrgica utiliza corretamente o uniforme privativo, máscara, gorro e propé;

- a equipe cirúrgica utiliza a máscara de forma correta:

- durante todo o tempo que permanece na SO;

- a boca e o nariz ficam completamente cobertos;

- evita a manipulação desnecessária;

- as conversas são minimizadas e a máscara deve ser trocada após espirro ou acesso de tosse.

Total de itens=6: $\mathrm{SIM}=6 ; \mathrm{PARCIALMENTE}=5-3 ; \mathrm{NÃO}=2-0$

3- Os procedimentos relacionados ao preparo da equipe cirúrgica (escovação das mãos), incluem:

- retirada de jóias e acessórios antes da escovação;

- a técnica de escovação é respeitada (movimento único, região considerada mais limpa para a mais suja, envolvendo mãos, unhas e antebraços);

- utilização de um degermante, preconizado pelo MS

Total de itens=3: $\mathrm{SIM}=3$; PARCIALMENTE=2; NÃO=1-0

4- Os procedimentos relacionados ao preparo da equipe cirúrgica (paramentação cirúrgica), incluem:

- o avental ser pego pelo lado interno e pelo colarinho;

- o avental ser aberto de forma delicada, sem sacudir, e mantido distante do corpo;

- a equipe cirúrgica inserir as mãos e braços dentro das mangas, mantendo-os elevados, deixando que o avental deslize sobre o corpo;

- o circulante auxiliar a paramentação de forma adequada;

- a técnica de calçar as luvas ser correta;

- a equipe cirúrgica, após a paramentação, manter a esterilização do vestuário, considerando estéril apenas a frente do tórax (na altura do cotovelo).

Total de itens=6: $\mathrm{SIM}=6 ; \mathrm{PARCIALMENTE}=5-3 ; \mathrm{NA} O=2-0$

\section{5- Os procedimentos relacionados ao preparo do campo operatório incluem:}

- a técnica de anti-sepsia da pele do paciente, utilizada pela equipe cirúrgica, preservar os princípios da assepsia cirúrgica (movimento único, da região considerada mais limpa para a mais suja);

- a solução utilizada para a anti-sepsia ser preconizada pelo MS;

- a equipe cirúrgica, inicialmente, colocar os campos estéreis ao redor do local cirúrgico e, posteriormente, na periferia;

- a equipe cirúrgica manter os campos estéreis afastados do corpo ao abri-los;

- a equipe cirúrgica dispor os campos estéreis sobre o paciente, preservando os princípios da assepsia cirúrgica (evitar encostar em áreas não estéreis, abrir bruscamente).

Total de itens=5: $\mathrm{SIM}=5 ; \mathrm{PARCIALMENTE}=4-2 ; \mathrm{NÃO}=1-0$ 
6- O manuseio de materiais estéreis e instrumentos pela equipe cirúrgica, durante o ato cirúrgico, é realizado da seguinte forma:

- a equipe cirúrgica monta as mesas de instrumentais e materiais, preservando a integridade e esterilização dos mesmos;

- a equipe cirúrgica manuseia, com prudência, os materiais e instrumentais, durante todo o ato cirúrgico, mantendo o campo operatório estéril.

Total de itens=2: $\mathrm{SIM}=2 ; \mathrm{PARCIALMENTE}=1 ; \mathrm{NÃO}=0$

7- O tráfego da sala de operação é controlado da seguinte forma:

- o acesso e o trânsito de pessoas são restritos na SO;

- as portas da SO são mantidas fechadas;

- as conversas e movimentos das pessoas presentes na SO diminuem durante o ato anestésico- cirúrgico;

- o fluxo do paciente, materiais limpos e sujos são respeitados.

Total de itens=4: $\mathrm{SIM}=4 ; \mathrm{PARCIALMENTE}=3-2 ; \mathrm{NÃO}=1-0$

8- A temperatura e a umidade do ar ambiente da SO são controladas segundo os parâmetros a seguir:

- A temperatura ambiente da SO é mantida em torno de $21^{\circ} \mathrm{C}$;

- A umidade relativa do ar ambiente da SO é mantida entre $45 \%$ a $55 \%$.

Total de itens=2: $\mathrm{SIM}=2 ; \mathrm{PARCIALMENTE}=1 ; \mathrm{NÃO}=0$ 